\title{
CONTRIBUTION OF THE NEW MAIN COMBAT AIRCRAFT TO BULGARIA'S DEFENCE CAPABILITIES
}

\author{
Major General Constantine POPOV
}

\begin{abstract}
The Commander of the Bulgarian Air Force substantiates the need for and the contribution of the future fighter aircraft to the defence capabilities of the country as a member of NATO and the European Union.
\end{abstract}

Keywords: Air power, fighter aviation, allied operations, capability gaps.

It is a great honour and pleasure to share with you my thoughts on the future new type of main combat aircraft in the Bulgarian Air Force and its contribution to the defence capabilities of the country as a member of the North Atlantic Alliance, as well as of the European Union. I would like to start with posing a few questions for your consideration:

- Why advanced and promising combat aircraft are continuously developed around the world, implementing latest technologies and attracting the best professionals and advanced scientific organizations?

- Why developed nations continue to build combat aviation with priority on multi-role fighters despite of the considerable costs for their acquisition and operation?

- Why is the selection of a new main type of combat aircraft of extreme interest for the development of the Bulgarian Air Force capabilities, as well as of the capabilities of the Bulgarian Armed Forces as a whole?

The answers to these questions are not simple; they are conditioned by the specific characteristics of the Air Force and the increasing role of the aviation in resolving all kinds of conflict around the world.

The relative prestige and importance of the Air Force in operations have been steadily increasing over the past 20 years. This is particularly visible when the concept of a 
total clash of mass armies is being replaced by the concept of using small but modern and effective joint and multinational military formations.

This consistent trend is due to the unique characteristics of today's air forces with their:

- diverse range of performed tasks;

- long distance range;

- $\quad$ quick reaction and flexibility;

- high readiness of action;

- $\quad$ power, accuracy and precision.

The modern combat aircrafts today are the major holder of these features of the Air Force. Possessing advanced operational capabilities, they provide a significant contribution to the nations' defence capabilities in the system of national and collective defence and security.

Acquisition of fewer numbers but promising modern aircraft with enhanced capabilities and discarding different types of outdated military aircraft are common trends in the world.

Key factors and capabilities, defining the leading role of these combat aircraft in Air Force contribution to the resolution of crises and conflicts in today's circumstances are:

- multi-functionality - the abilities of combat aircraft quickly and efficiently to perform a wide range of various tasks depending on the situation;

- distance and duration of the flight - the aircraft capabilities to fly over long distances and carry out several tasks within one sortie (and, if necessary, to refuel in the air);

- $\quad$ precision in actions - precision strikes day and night in any environmental conditions, which is a prerequisite for participation in multinational operations aiming to reduce collateral damages, especially in cases of co-operative actions between military units and civilian organizations;

- reconnaissance - a wide range of options to complement the common operational picture in the area of military operations in real-time and simultaneously engage targets when necessary;

- $\quad$ high efficiency by working in a network-centred environment;

- high survivability using modern means of identification and self-defence.

The specific factors and capabilities determining the necessity of select a new main type of combat aircraft for the Bulgarian Air Force are related to: 
- the country's important geopolitical location in the midst of the transforming Balkans and it's role as an eastern external border of NATO and the European Union;

- the abrupt reduction of the number of ready combat aircraft, due to the fact that a significant number of MiG-21s and Su-25s-currently used to provide security of the country's airspace in the NATO Integrated Air Defence System and to support the operations of sister services-are approaching the end of their useful life cycle;

- the limited capabilities of the MiG-29s—still remaining at operational readiness - to ensure reliable performance of the airspace defence for the following reasons:

o the limited number of platforms does not ensure maintenance of the pilots' minimum quantitative and qualitative training for performing a combat duty;

o risk for the aircrafts' logistics support to ensure the operational readiness, associated with the dependence on non-NATO countries;

o the lack of interoperability limits the ability of performing Air Policing mission in accordance with assigned force goals and NATO standards;

- the MiG-29 platform does not fully meet the capability requirements towards a modern combat aircraft.

Under these conditions, the Bulgarian Air Force has a deficiency of capabilities which reduces the Armed Forces' capacity as a whole to meet in full the country's commitments to the defence policy of NATO and the European Union.

In order to overcome the shortage of defence capabilities, the acquisition of the new main type of combat aircraft is one of the most important and priority projects for generating the necessary new capabilities, directly related to the national security and our allied commitments.

Taking into considerations the importance of the project, the Government of the Republic of Bulgaria included the acquisition of a new main type of combat aircraft in its Programme 2009-2013. The main challenge in the realization of this project will be to find a proper balance between capabilities, price, delivery terms, mastering the aircraft and reaching operational readiness. In this, the Bulgarian Air Force is prepared for active involvement in the acquisition process and the prompt adoption of the new main type of combat aircraft. 
The procurement of the aircraft and its operation by the Bulgarian Air Force will significantly increase its contribution to the defence capabilities of the Bulgarian Armed Forces by:

- increasing the reliability of the country's airspace defence in the NATO Integrated Air Defence System with capabilities for control and defence over expanded areas of responsibility in the Black Sea region;

- overcoming the existing deficiency of capabilities through acquisition of new capabilities such as capabilities to conduct air reconnaissance operations in network-centred environment, precision strikes, increased protection and survivability;

- enhancing the capabilities to work in an allied environment for ensuring implementation of our country's commitments in terms of force goals, allied standards and participation in collective defence actions to ensure national and international security.

Acquiring these capabilities, the Bulgarian Air Force will significantly increase the Armed Forces' contribution to the national and collective security systems and defence and will be a predictable partner in NATO and EU.

And last, but not least, anticipated financial and technological benefits for the economy, associated with the implementation of this major project for modernization of the Bulgarian Air Force, should also be taken in consideration.

In conclusion, I would like to emphasize that the acquired capabilities of a new main type of combat aircraft will contribute significantly to the development of the national defence capabilities and to the implementation of assigned defence missions and tasks. We live in a global world where national and collective security and international stability are vital for the prosperity of nations. Bulgaria's membership in NATO and the EU is based on a common commitment to security, which includes sharing benefits and advantages, as well as the burdens and responsibilities for common security and defence. With the acquisition of the new main type of combat aircraft, Republic of Bulgaria will increase its contribution to ensuring international peace, security and stability.

Major General CONSTANTINE POPOV is Commander of the Bulgarian Air Force. He is graduate of the Bulgarian Air Force Academy (1984), the "G.S. Rakovski” Defence and Staff College in Sofia (1992), the US Air War College, Maxwell AFB, Alabama (2001), and the NATO School in Oberammergau, Germany (2005). A fighter pilot with 1,200 flying hours, General Popov has served at a variety of field and staff positions in Bulgaria and in NATO. 